\title{
A Study on Taiwanese High School EFL Learners' Literacy Performance
}

\author{
Adam Ting
}

\begin{abstract}
This study intended to explore Taiwanese high school students' English literacy performance, including reading comprehension and writing, as well as their reading awareness and vocabulary competence. 111 seniors at high school level participated in this study. They were divided into three groups based on their English writing scores on the General Scholastic Ability Test (GSAT) (2010). All participants were required to take a vocabulary level test and answer a questionnaire regarding reading attitude, reading strategies, and English writing style. The major findings included, first, there were significant relationships between students' vocabulary knowledge, reading attitude, reading strategies, and their reading comprehension scores and short essay writing scores; second, proficient students displayed significant difference from less proficient students in the above mentioned categories; third, participants' vocabulary size, particularly words at the second 1,000 word level, significantly interacted with their reading attitude in terms of their writing performance. Fourth, proficient student writers were different from the less proficient in the average length of sentences. In light of the findings from the study, some pedagogical implications are suggested.
\end{abstract}

\section{Introduction}

Research on literacy has demonstrated that L2 literacy acquisition is a process far more complex than L1 (Carson, et al, [4]). Generally speaking, a person acquiring his or her L1 literacy is often accompanied by oral fluency in native language due to sufficient exposure to oral input/output since the birth (Bialystok, [2]). L2 literacy development apparently does not have as much advantage of full oral competence coming from L1. Problems may appear more serious for teenagers or adult L2 learners who have developed proficient L1 literacy but do not any resource from L2 language background (Hedgcock \& Atkinson, [11]). On the other hand, according to Cummins' [7] interdependence theory, a person must reach a threshold level of L2 language proficiency so that his or her good L1 literacy skills can successfully transfer to L2. Research on L2 literacy development may thus be constrained to pay more attention to learners' target language learning in school settings. Previous studies on L2 literacy performance of academic students focused on L2 learners' reading and writing behaviors (Carson et al, [4]; Hedgcock \& Atkinson, [11]). Reading and writing have been recognized closely related to each other (Pearson \& Tierney, [19]; Krashen, [14]). As Pearson and Tierney [19] mentioned, "a thoughtful reader is one who reads as if composing a text for yet another reader who lives within (p.1)." Following this view, it can be inferred that a good reader knows well how a text is organized, just as a good writer who can plan the text structure logically so that its potential readers may comprehend efficiently and effectively. English teaching for senior high school students in Taiwan has long tended to focus on reading and writing due to the need to pass a college entrance examination. Taiwanese high school students have learned to read English articles for many years; however, they are not able to write conventionally appropriate English compositions. Statistics released by the Ministry of Education Testing Center in Taiwan indicated that up to 22,462 test-takers (16\%) of the General Scholastict Aptitude Test (GSAT), a proficiency test assessing high school students' reading and writing competence, in 2009, have scored a perfect zero in the writing test. The key issue this brings up is effective writing instruction or intervention for high school students. Closer observations from practitioners have suggested that a limited vocabulary size and insufficient knowledge on how a written text is organized may have been attributed to students' unsatisfactory writing performance. Evidently, lack of threshold level of English language proficiency seriously constrained the literacy performance for Taiwanese high school students in their college entrance examination.

To help Taiwanese high school students to prepare themselves for better accommodation to college education, an academic community where better language proficiency is required, a number of studies have been conducted to explore the effect of guidance reading on students' writing recently (Chung, [6]; Chou, [5]) when it is integrated into English writing instruction. However, few studies have investigated the relationship between students' reading awareness, vocabulary knowledge, and the effect of such knowledge on their reading and writing performance, without which teachers are unlikely to have a clear picture of students' overall 
English literacy level. To bridge the gap, this study intended to discover the relationship between Taiwanese high school students' vocabulary knowledge, their perspectives of English reading, and the reading and writing performance by answering the following research questions:

1. What are Taiwanese senior high school students' reading awareness and the strategies they use to cope with reading problems?

2. Is there any significant relationship between Taiwanese senior high school students' reading awareness and their performance in reading comprehension test? If so, what are the differences between skilled readers and less skilled readers?

3. Is there any significant relationship between Taiwanese senior high school students' vocabulary knowledge and their writing performance? If so, what are the differences between proficient student writers and less proficient ones?

\section{Literature Review}

Literacy refers to a person's overall competence of reading and writing. Academic literacy may involve broader scope of linguistic competence. Johns [12] defined literacy as having the following features. First, literacy can stand for a person's four language skills: listening, speaking, reading, and writing. Second, literacy includes a person's specific content knowledge when dealing with various discourse types. Third, a person has acquired literacy to a certain extent if he or she possess effective strategies to deal with the text encountered. Fourth, literacy can have an equivalent meaning of a person's awareness of social context. Fifth, a person's schemata system (background knowledge or world knowledge) is an important element involved in his/her literacy.

A person's L1 literacy development may be significantly affected by the exposure to mother tongue during the childhood (Bialystok, [2]); however, a L2 learner's target language acquisition is contrastively more complex, especially an adult L2 learner (Carson, et al [4]). A well-developed L2 literacy involves not only excellent language proficiency but also proper formal and content knowledge of discourse, spoken and written. A discussion of L2 literacy development must take into consideration a L2 learner's cognitive and metacognitive awareness, as well as the actual performance in reading and writing tasks. A learner's cognitive awareness of L2 learning may include learner attitude and self-efficacy, while metacognitve awareness can point to a learner's reading comprehension monitoring strategies (Baker and Brown, [1]) and vocabulary use in the writing.

Hedgcock and Atkinson's [11] studies intended to explore reading and wring relationship in L1 and L2 literacy development. 157 native speakers of English and 117 students with different language background attended the study. They were requested to complete a questionnaire regarding their reading habit while in elementary school, high school and currently. In addition, they took a timed expository writing test to investigate the possible interaction between reading and writing. The results in L1 study indicated that writing is significantly related to positive reading habit, and that experience with specific text type may have particular connection with writing performance in early L1 school education. As for the L2 study, which was done by completely copying L1 study procedure, there did not reveal significant relationship between reading and writing, Hedgcock and Atkinson claimed for more theoretical explanation.

L2 learners' literacy performance is necessarily concerned with learner's usual reading and writing behaviors. Though L1 and L2 reading model share much resemblance, reading is a complex process (Goodman [9]; Smith, [25]). Reading involves not only recognition of written words on the page in terms of phoneme-grapheme relations, syntactic association, semantic interpretation, but also how readers connect with their world knowledge, individual experience, and motivation (Wallace [27]). That is, readers interact with the text by way of their reading awareness. Reading awareness refers to the reader's attitude toward the text and the selfinitiated reading strategies he or she may use to cope with reading problems.

Reading strategies play influential roles in EFL learners' reading comprehension. A study conducted by Block [3] made use of think aloud method to explore how less skilled EFL readers use strategies to deal with reading problems. In the study, the participants were required to retell as detailed as possible how they could understand the story they had just read. All the participants strategies used were coded and categorized. Block concluded that EFL learners tend to use integration strategy (i.e. connecting new information with previously stated content), and association strategy (associating prior experience or knowledge to conquer the reading predicaments). Such readers display extensive mode of reading style, that is, "readers attempt to deal with the message conveyed by the author; their focus is on understanding the ideas of the author, not on relating the text to themselves, and they tend to respond in the third person strategy type (p. 472)."

As an influential element, vocabulary knowledge can significantly affect both reading and writing. Research has provided evidence for the impact of vocabulary size on reading and writing (Qian [20]; Laufer [15]). Proficient EFL learners often possess large amount of known words, and therefore they can efficiently deal with their reading and writing task. Furthermore, as Nation [18] mentioned, "vocabulary is a strong indicator of whether the writer has 
adopted the convention of the relevant discourse community (p. 178).”

EFL learners' writing performance has been identified to have significant connection with reading. Krashen [14] proposed a reading hypothesis, by which he claimed that "reading is the only one way to develop literacy (p.17).” A student must read a lot of books, appreciating and observing the content as well as the organization of the text explicitly or implicitly, so that the learner can gradually develop a set of comprehensible, sociolinguistically appropriate writing skill. Eitherhold [8] finding of her research on reading and writing connection for second language learners concluded that first, better writers tend to be better readers, second, better writers appear to read more than poor writer, and third, better readers tend to produce syntactically more mature writing than poor readers. As Krashen put it, "Reading is a powerful means of developing reading comprehension, writing style, vocabulary, spelling, and grammar (p. 37).”

Taiwanese high school teachers have been trying to teach English composition through a variety of reading activities. Studies of these teaching activities intended to compare the teaching efficacy after students had received the instruction (Chung [6]; Chou [5]). Previous studies have used surveys and pre- and post-test as major instruments; no study has ever incorporated the test of students' English vocabulary knowledge. Additional objective measures such as participants' vocabulary size can be used to further illuminate the findings regarding to what extent vocabulary knowledge can affect EFL learners’ English reading and writing.

\section{Methodology}

The participants in this study included 111 senior students in a senior high school in Taiwan. Most of the students were intermediate EFL learners, with academic orientation in humanity courses. All participants were categorized into Group 1 (G1, less proficient), Group 2 (G2, intermediate proficient) and Group 3 (G3, high proficient), based on their scores of essay writing in 2010 General Scholastic Aptitude Test (GSAT). The participants' performance in reading comprehension and writing test were taken as the dependent variables in this study. Also, a recall protocol of their short essay writing in GSAT and three pieces of composition in simulated GSAT were collected so that their vocabulary use could be analyzed.

Nation's [18] Vocabulary Level Test (VLT) was used in this study in order to measure all participants' receptive vocabulary size at the 1,000 , 2,000, and 3,000 word level. According to Nation [18], the test taker is evaluated as passing a specific word level if he or she obtains $72 \%$ of accuracy rate. To analyze participants' productive vocabulary, words use in their writing, the VocabProfile package was also used. Such computer program is able to compare vocabulary list against a text to see what words and what percentage in the text are in the lists and what percentage of the items are covered by the list (Laufer \& Nation, [16]).

Besides the analysis of participants' vocabulary knowledge, the researcher's self-designed questionnaire was adopted, using a five-point Likertscale. Three major categories were included with a view to assessing the participants' general attitude about their reading awareness, the way in which participants used to organize their compositions,. These three major categories together with the VLT average scores compromised the independent variables in this study. To assess whether the items that were summed to create the general scores formed a reliable scale, Cronbach's alpha was computed. The alpha for the 49 items was .833, which indicated that the items form a scale that has reasonable internal consistency reliability.

\section{Results and Discussion}

The result of the participants' overall vocabulary performance at the three levels was displayed in Table 1. In general, 57 participants, roughly 51.35\%, successfully passed the 1,000-word level, 25 participants, roughly $22.52 \%$, passed the 2,000-word level, and 16 participants, $14 \%$, reached the 3,000 word level.

Table 1. Result of participants' performance of VLT

\begin{tabular}{|l|l|l|l|l|}
\hline & & 1,000 & 2,000 & 3,000 \\
\hline & Total & $\mathrm{N}(\%)$ & $\mathrm{N}(\%)$ & $\mathrm{N}(\%)$ \\
\hline G1 & 53 & $13(24.52 \%)$ & $1(1.88 \%)$ & $0(0.00 \%)$ \\
\hline G2 & 28 & $19(67.85 \%)$ & $5(17.85 \%)$ & $1(3.60 \%)$ \\
\hline G3 & 30 & $26(86.66 \%)$ & $19(63.33 \%)$ & $15(50.00 \%)$ \\
\hline Total & 111 & $57(51.35 \%)$ & $25(22.52 \%)$ & $16(14.00 \%)$ \\
\hline
\end{tabular}

Moreover, a one way ANOVA was used to examine the difference among the three groups at different vocabulary level. The results indicated that there was a significant difference among the students at 1,000 word level, $F(2,108)=22.239, \mathrm{p}<.05$. A post hoc testing using Bonferroni comparisons indicated that both $\mathrm{G} 3(\mathrm{M}=14.63, \mathrm{SD}=1.47)$ and $\mathrm{G} 2$ $(\mathrm{M}=12.54, \mathrm{SD}=2$. 91) outperformed $\mathrm{G1}(\mathrm{M}=10.70$; $\mathrm{SD}=2.90$ ), and G3 outperformed G2. There was also a significant difference at 2,000 word level among the participants in the three groups, $F(2,108)=$ 41.557, $\mathrm{p}<.05$. Participants in G3 $(\mathrm{M}=12.93$; $\mathrm{SD}=4.08)$ obtained higher scores than those in $\mathrm{G} 2$ $(\mathrm{M}=8.18 ; \mathrm{SD}=3.98)$ and $\mathrm{G1}(\mathrm{M}=5.17 \mathrm{SD}=3.37)$, and participants in G2 had better grade than participants in G1. The same result could be observed at 3,000 word level, $\mathrm{F}(2,108)=22.239, \mathrm{p}<.05$. $\mathrm{G} 3(\mathrm{M}=11.37$, 
$\mathrm{SD}=4.71)$ excelled both $\mathrm{G} 2(\mathrm{M}=7.00, \mathrm{SD}=4.06)$ and G1, $(\mathrm{M}=3.87, \mathrm{SD}=2.57)$ and $\mathrm{G} 2$ performed better than G1.

In addition to distinguishing proficient students from less proficient ones, the participants' average scores in VLT were used to measure its relationship to participants composition scores. Their writing performance was also used to investigate the possible relationship to the participants' attitude toward the learning of vocabulary, reading, and writing.

Table 2. Correlation among English composition scores, average scores of VLT and four major categories in the questionnaire for the participants

\begin{tabular}{|l|l|l|l|l|l|l|}
\hline & Comp. & Aver & R-att & R-stra & W-sty & M(S.D) \\
\hline R-com & $.514^{* *}$ & $.659^{* *}$ & $.514^{* *}$ & $.335^{* *}$ & $.321^{*}$ & $38.14(12.41)$ \\
\hline Comp & 1 & $.642^{* *}$ & $.411^{* *}$ & $.231^{*}$ & $.268^{* *}$ & $4.97(2.99)$ \\
\hline Aver. & & 1 & $.532^{* *}$ & $.226^{*}$ & $.289^{* *}$ & $8.98(3.8)$ \\
\hline R-att & & & 1 & $.354^{* *}$ & $.239^{*}$ & $2.74(.43)$ \\
\hline R-stra & & & & 1 & $.373^{* *}$ & $3.56(.52)$ \\
\hline W-sty & & & & & 1 & $3.78(.52)$ \\
\hline
\end{tabular}

Notes: R-com=Reading

comprehension, Comp=composition, Aver=Average of VLT, R-att=Reading attitude, R-stra $=$ Reading strategy, $\mathrm{W}$-sty $=$ Writing style. $* *$ $\mathrm{p}<.01,{ }^{*} \mathrm{p}<.05$

Pearson's correlation was used to test the hypothesis of a linear relationship between participants reading comprehension $(\mathrm{M}=38.12$, $\mathrm{SD}=12.41)$, composition scores $(\mathrm{M}=4.97, \mathrm{SD}=2.99)$, average scores of VLT, $(\mathrm{M}=8.98, \mathrm{SD}=3.87)$, reading attitude $\quad(\mathrm{M}=2.74, \quad \mathrm{SD}=.43)$, reading strategy $(\mathrm{M}=3.56, \mathrm{SD}=.52)$, and write style $(\mathrm{M}=3.78$, $\mathrm{SD}=.52)$. The results as shown in Table 2 indicated that, almost all the main categories in the questionnaire revealed significant positive linear relationship among them, particularly the relationship between participants average score in VLT test and their reading comprehension scores $\mathrm{r}(111)=.659, \quad \mathrm{p}<.01$ and composition scores, $\mathrm{r}(111)=.642, \quad \mathrm{p}<$.01. The significant relationship between these variables may imply that the higher vocabulary size the participants possess, the better composition and reading comprehension scores they may obtain.

Participants' reading awareness, including reading attitude and reading strategies, indicated similar results. Participants reading attitude revealed significant relationship to their reading performance $\mathrm{r}(111)=.514, \quad \mathrm{p}<\quad .01, \quad$ composition scores, $\mathrm{r}(111)=.411, \mathrm{p}<.01$, and to average vocabulary scores, $\mathrm{r}(111)=.532, \mathrm{p}<.01$. Likewise, their reading strategies showed significant relationships to their reading performance $\mathrm{r}(111)=.335, \quad \mathrm{p}<.01$, composition scores, $\mathrm{r}(111)=.231, \mathrm{p}<.05$, and to average vocabulary scores, $\mathrm{r}(111)=.226, \mathrm{p}<.05$. The same results could also be found in the relationship of participants' writing style to their compositions scores and vocabulary size, with slightly significant relationship of writing style to composition scores, $\mathrm{r}(111)=.268, \mathrm{p}<.01$, and to vocabulary scores, $\mathrm{r}(111)=.289, \mathrm{p}<.01$. The above results could provide evidences that participant reading comprehension and composition scores were positively connected with their reading awareness, vocabulary strategies, and their usual writing habits to a certain extent.

As indicated in Table 2, the significant connections between vocabulary competence, reading and writing performance, and also reading attitude provided excellent support to Laufer's [15] claim that a better vocabulary size, ideally, 3,000 word family, can allow L2 readers to comprehend $95 \%$ of reading content. Also, as researchers of second language reading proposed ( Krashen, [14]), L2 readers who have developed a regular and extensive reading habit often lead to far more effective comprehension of texts than those who do not.

Since the above mentioned variables, including reading attitude and reading strategies, indicated significant relationship to participant reading comprehension scores and to their average scores in VLT, it was necessary to further compare the difference among learners at different proficient levels.

Table 3. ANOVA Table for the comparison among different groups at reading performance at different scale scores

\begin{tabular}{|l|l|r|r|r|l|l|l|}
\hline category & & \multicolumn{1}{l|}{ Sum } & \multicolumn{1}{l}{ DF } & \multicolumn{1}{c|}{ M.S } & F & Sig & P. hoc \\
\hline R-com & Bet & 13823.0 & 2 & 6911 & $\begin{array}{l}206.50 \\
*\end{array}$ & .000 & G3>G2 \\
\hline & Wit & 3748.4 & 112 & 33.46 & & & G3>G1 \\
\hline & Tot & 17571.5 & 114 & & & & G2>G1 \\
\hline R-att & Bet & 4.178 & 2 & 2.089 & 16.072 & .000 & G3>G1 \\
& & & & & $*$ & & \\
\hline & Wit & 13.907 & 107 & .130 & & & G2>G1 \\
\hline & Tot & 18.085 & 109 & & & & \\
\hline R-stra & Bet & 3.194 & 2 & 1.597 & $6.614^{*}$ & .002 & G3>G1 \\
\hline & Wit & 26.800 & 111 & .241 & & & \\
\hline & Tot & 29.994 & 113 & & & & \\
\hline W-sty & Bet & 2.730 & 2 & 1.365 & $6.954^{*}$ & .001 & G3>G1 \\
\hline & Wit & 21.200 & 108 & .196 & & & G2>G1 \\
\hline & Tot & 23.930 & 110 & & & & \\
\hline
\end{tabular}

${ }^{*} \mathrm{p}<.05$

A one-way ANOVA was used to investigate the difference among the participants in terms of their reading comprehension performance, reading attitude, reading strategy, and writing style. Significant differences were found among participants at different proficient levels in all the four main categories, as indicated in Table 3.

At the reading comprehension score category, apparent distinctions were found among the three groups, $\mathrm{F}(2,111)=206.5, \mathrm{p}<.05$. Advanced learners (G3, $\mathrm{M}=54.29$, $\mathrm{SD}=7.77$ ) in this study performed better than intermediate learners (G2, $M=40.21$, $\mathrm{SD}=3.27)$ and less proficient learners $(\mathrm{G} 1, \mathrm{M}=28.12$, $\mathrm{SD}=5.45$ ). This result echoed Caron's (1990) claim that good writers tends to read more than poor writers and thus are able to reveal higher level of reading comprehension. 
The participants' general attitudes toward reading were significantly different to one another, $\mathrm{F}(2$, $111)=16.072, \mathrm{p}<.05$. Proficient group $(\mathrm{M}=3.02$, $\mathrm{SD}=.39$ ) showed more positive attitude toward reading than less proficient group ( $\mathrm{M}=2.52, \mathrm{SD}=.36)$. This may imply that the students in this study generally agreed that continuous extensive reading of interesting English materials can bring forth positive effect on improving their English proficiency level.

A significant difference among the three groups in terms of the use of reading strategies can be observed, $F(2,111)=6.614, p<.05$. A post hoc test using Bonferroni comparisons revealed that G3 $(\mathrm{M}=3.79 ; \mathrm{SD}=.57)$ use strategies to help reading comprehension more significantly than $\mathrm{G} 1(\mathrm{M}=3.4$; $\mathrm{SD}=.44$ ), but not more significantly than G2 $(\mathrm{M}=3.65 ; \mathrm{SD}=.69)$. Among the strategies use to facilitate reading comprehension, continuing reading to look for clues to clarify the hypothesis made in the previous part of the passage $(\mathrm{M}=3.94 ; \mathrm{SD}=.882)$ and guessing from the context $(\mathrm{M}=3.94 ; \mathrm{SD}=1.00)$ are the two most popular strategies that proficient students will use. Looking up a dictionary for unknown words is the third strategy that helps students understand a given article $(\mathrm{M}=3.87$; $\mathrm{SD}=1.09)$. Such results are consistent with Block's [3] findings that skilled readers tend to look at broader scope of reading content. In contrast, less proficient students tended to use fewer strategies to aid reading comprehension. Among those strategies used by unskilled students were looking up a dictionary $(\mathrm{M}=3.57, \mathrm{SD}=.988)$ and guessing from context $(\mathrm{M}=3.55, \mathrm{SD}=.913)$.

The first and the second research questions asked how student writers at different levels can be different to each other in terms of their reading awareness and reading strategies. The answers can be drawn that generally speaking the competent learners in this study seem to prefer to use top-down reading model in the reading task, while unskillful learners would use bottom-up reading model to solve their reading problems. This can be explain by the fact that proficient learners possess larger vocabulary size, with which they spend little time decoding words in the print and thus can be more focused on the whole picture of the text (Qian [20]).

An interesting phenomenon is that the less preferable strategy that students would use when they have problem comprehending a reading text is to consult the teacher $(\mathrm{M}=3.50$; $\mathrm{SD}=1.11)$.

In addition to the reading awareness, participants individual writing habits varied to a significant level, $\mathrm{F}(2,109)=6.954, \mathrm{P}<.05$. The most significant difference among the three groups was the arrangement of topic sentences. Participants in G3 $(\mathrm{M}=3.70, \mathrm{SD}=.794)$ and $\mathrm{G} 2(\mathrm{M}=3.46, \mathrm{SD}=.881)$ tended to present topic sentence in the beginning of a paragraph more frequently than those in G1 $(\mathrm{M}=2.77, \mathrm{SD}=1.07)$. Besides dissimilarity in textural construction, G3 were different from G1 in terms of vocabulary use including listing key words before writing, willing to employ newly learned words in the writing task, and paying attention to vocabulary richness. Based on the above analysis, it seems evident that proficient learners would take risk producing a text based on what they have observed from the reading, either rhetorical structure or vocabulary use.

Given the results as shown in Table 2 that relatively higher coefficient correlation existed between the participant' writing scores and their vocabulary size, $\mathrm{r}(111)=.642, \mathrm{p}<.0$, and the reading attitude, $\mathrm{r}(111)=.411, \mathrm{p}<.01$, as well as those between reading comprehension scores and vocabulary size $\mathrm{r}(111)=.659, \mathrm{p}<.0$, reading attitude $\mathrm{r}(111)=.514, \mathrm{p}<.0$, a two-way ANOVA was executed to measure the effect of participants' vocabulary scores and reading attitude on the composition scores and reading comprehension scores.

The result indicated that no significant interaction was found between main effects of reading attitude and vocabulary size on participants' reading comprehension score, $\mathrm{F}(1,103)=.458, \mathrm{p}=.500$. A test wise effect may be able to account for the condition where there was no significant interaction of reading awareness and vocabulary knowledge on participants reading performance in GAST. Since this type of test in Taiwan has long been considered to have the decisive impact on high school students advanced education, to be well-prepared, almost every high school students had attended a number of simulated examinations to train themselves to be familiar with tips of answering questions. Therefore, for some participants who have developed quite effective skills in answering questions, their high scores in reading comprehension test do not indicate that they are genuinely competent readers (Goodman, [10]).

On the other hand, the ANOVA sources of variation result pointed to a significant interaction between a vocabulary size at 2,000-word level and reading attitude on composition scores, $\mathrm{F}(1,103)$ $=4.442, \mathrm{p}<.05$. Table 4 summarized the mean scores, standard deviations of composition scores of the 4 groups for the interactive effect of VLT-2,000 and reading attitude.

Table 4. Composition between the proficient student writers and less proficient ones in terms of their English reading awareness on the VLT-2,000

\begin{tabular}{|l|l|l|l|l|}
\hline \multicolumn{1}{|c|}{ VLT-2000 } & Not Passed & & Passed & \\
\hline R-att & Mean (SD) & N & Mean (SD) & N \\
\hline Low & $3.98(2.550)$ & 67 & $8.92(3.427)$ & 6 \\
\hline High & $5.06(2.640)$ & 18 & $7.06(1.982)$ & 16 \\
\hline
\end{tabular}

The one-way ANOVA and follow-up contrasts that compared the 4 cell means manifested the significant difference among the four cell means, 
$\mathrm{F}(3,103)=11.821, \mathrm{p}<.001$. Contrast tests clearly illustrated the difference between participants who had developed better vocabulary competence at 2,000-word and those who failed to reach the threshold level of vocabulary size, $\mathrm{t}(103)=-4.560$, $\mathrm{p}=.000$, despite the fact that they were all less interested in reading (mean difference $=4.94$ ). A an identical result also appeared among participants who were heavy readers, $\mathrm{t}(102)=-2.298, \mathrm{p}<.02$ : participants with better vocabulary competence were significantly different from those who need to improve the vocabulary size (mean difference=2.00). The above results evidently provide an answer to the third research question, Is there any significant relationship between Taiwanese participants' vocabulary knowledge and their writing performance? A significant interaction existed between vocabulary size and writing performance, in that learner who are enthusiastic at reading and have better vocabulary size are likely to produce better written works, while those who do not read habitually and possess less vocabulary size than 2,000 words have relatively difficulty producing conventionally appropriate written works.

To further distinguish proficient student writers and less the proficient, the participants' productive vocabulary in the writing works were examined using VocabProfile package. After a corpus of the participants' short essay writing products was built, a one-way ANOVA was used to examine if there were differences among the participants at different proficiency levels in their vocabulary use at the 1,000 word level, 2,000 the word level, content words, functional words, lexical density, and average sentence length. The results were indicated in Table 5 , which showed that participants did not make significant differences in their vocabulary use at the 1,000 word level, $\mathrm{F}(2,109)=2.087, \mathrm{p}=.129$, nor at the 2,000 word level, $\mathrm{F}(2,109)=1.104, \mathrm{p}=.335$. Such results echo related findings in the literature (Laufer, [17]) that productive vocabulary is less than receptive vocabulary to a certain extent.

Table 5. The distribution of words at different levels and word categories in students' short essay writing corpus

\begin{tabular}{|c|c|c|c|c|c|c|c|}
\hline Categories & Level. & $\mathrm{N}$ & Mean & SD & $\mathrm{F}$ & $\mathrm{p}$ & P. hoc \\
\hline 1,000 & G1 & 44 & 88.90 & 4.78 & & & \\
\hline \multirow{2}{*}{ Word level } & G2 & 32 & 89.27 & 3.46 & 2.087 & .129 & \\
\hline & G3 & 36 & & 3.73 & & & \\
\hline 2,000 & G1 & 44 & 4.14 & 2.46 & & & \\
\hline \multirow{2}{*}{ Word level } & G2 & 32 & 3.77 & 1.41 & 1.104 & .335 & \\
\hline & G3 & 36 & & 2.05 & & & \\
\hline Content & GI & 44 & 52.03 & 4.56 & & & \\
\hline \multirow[t]{2}{*}{ Words } & G2 & 32 & 52.60 & 3.46 & .341 & .712 & \\
\hline & G3 & 36 & 51.82 & 3.76 & & & \\
\hline Function & G1 & 44 & 37.05 & 4.49 & & & \\
\hline \multirow[t]{2}{*}{ Words } & G2 & 32 & 35.94 & 4.84 & 1.853 & .162 & \\
\hline & G3 & 36 & 34.97 & 5.21 & & & \\
\hline Lexical & G1 & 44 & 47.95 & 4.57 & & & \\
\hline \multirow[t]{2}{*}{ Density } & G2 & 32 & 47.34 & 3.48 & .338 & .714 & \\
\hline & G3 & 36 & 48.11 & 3.84 & & & \\
\hline Average & G1 & 44 & 12.11 & 309 & & & \\
\hline Sentence & G2 & 32 & 1291 & 288 & 7.056 & $.001^{*}$ & $\mathrm{P}>\mathrm{L}$ \\
\hline Length & G3 & 36 & 14.69 & 3.26 & & & \\
\hline
\end{tabular}

Notes. $1 . \mathrm{P}=$ proficient group; $\mathrm{L}=$ low proficient group 2. ${ }^{*} \mathrm{p}<.05$.

Other categories related to vocabulary use, including content words, function words, lexical density, and average sentence length, were analyzed. In view of participants' limited productive vocabulary, the content words, function words are calculated at the 1,000, and 2,000 word level. Function words are words that indicate grammatical functions; they include pronouns, auxiliary, prepositions, and conjunctions, while content words, as the name called, play the important role in expressing semantic interpretation of words, phrases, or sentences. Content words include nouns, verbs, adjectives, and adverbs. Lexical density refers to the ratio of content words to overall words in a text. For example, a text of 119 words, with 64 function words and 55 content words, can have a lexical density of 46.21. Lexical density can be taken as the index of richness of vocabulary use, because it is content words that provide information in a text. On the other hand, "few function words in a composition may reflect more subordinate clauses, participial phrases, and ellipsis (Laufer \& Nation, [16], p.309)”, thus a text with fewer function words is likely to be a text with longer sentences.

As indicated in Table 5, the participants revealed the slight but not significant differences among them in the use of function words, $\mathrm{F}(2,109)=1.853$, $\mathrm{p}=$ .162 , and in content words, $\mathrm{F}(2,109)=.341, \mathrm{p}=.712$. Generally speaking, participants tended to use more content words than function words in their short essay writing. Proficient group were contrastively prone to use less function words compared to less proficient group.

Regarding the category of lexical density, the ratio of content words to overall words in a text, also did not display significant difference among participants, $\mathrm{F}(2,109)=.338, \mathrm{p}=.714$. Actually, all the three groups displayed similar lexical density in their writing. Silva's [23] study analyzing the features of L2 writing indicated that EFL learners normally appear more conservative than native speakers in their writing. It may be attributable to the EFL learner's perspective of avoidance strategy to cope with difficult situation; they are afraid of making mistakes in terms of vocabulary use. As a result, the higher anxiety EFL learners have concerning using the wrong words, the less likely they can produce native-like writing.

Different from the above results, in the syntactic level of vocabulary use, proficient group evidently produced longer sentences than less proficient group, but not significantly than intermediate group, $\mathrm{F}(2$, $109)=7.056, p<.05$. The finding indicated that proficient participants were able to express their idea with words more sufficiently than less proficient participants, which supported what Reid [21] 
claimed that "length of essay has correlated highly with quality writing (p. 195).”

\section{Conclusion}

Corresponding to the results as discussed above, two major conclusions can be drawn. First, participants with a positive and extensive reading habit can have better performance in reading comprehension test; particularly when they can use flexible reading strategies such as making use of context clues to clarify puzzles, or guessing meaning form previous and subsequent contents. Second, vocabulary size displays close relationship to participants' literacy performance: when participants who are habitual readers have built up a vocabulary size over 2,000 word level, they are likely to produce quantitatively better written works.

A good reading habit and rich vocabulary knowledge play the important roles in EFL learners' reading and writing performance. According to Rivers [22], good writing in any language involves knowledge of convention of written discourse in that culture, and the abilities to choose the precise words that convey one's meaning. Knowledge of convention of written discourse mainly comes from reading (Stotsky [26]) while vocabulary choice, as Nation [18] mentioned, "is a strong indicator of whether the writer has adopted the convention of the relevant discourse community (p. 178)." For Taiwanese senior high school students, reading awareness significantly influences their reading and writing performance to a certain extent; particularly their reading attitude, whether they can cultivate an ongoing, extensive and strategy-oriented reading habit can affect their overall writing skills (Eisterhold [8]). The knowledge they gained from reading would definitely facilitate their efficiency in reading comprehension for texts in different rhetorical organization and also shape the style how they write in the composing tasks. Besides, as Schmitt [24] put it,"2,000 words seem to be the most commonly cited initial goal for second language learners (p. 142)." Taiwanese high school students as EFL learners are suggested to develop a minimum vocabulary size, the threshold level of 2,000 vocabulary, if they aim at producing a composition conventionally acceptable to the written discourse of the target language.

The finding of this study can provide teachers some pedagogical applications. Acquisition of L2 literacy comes from extensive and sufficient exposure to reading and writing of the target language (Carson, et al, [4]). In addition to student individual efforts, teachers may facilitate young learners' reading and writing skills by introducing reading materials that are well-organized in rhetorical structure and vocabulary use. Through reading sample texts, students can observe how good writings are structured and how words are used to present the most effective rhetorical effect. By so doing, they can develop better knowledge base of English writing convention in terms of textural coherence and versatile use of vocabulary in the writing task. When learners have developed proper literate level in English, they may have no difficulty producing more conventionally appropriate composition.

This study analyzed the participants' literacy performance in GSAT 2010 as convenient samples without taking reference to students' general performance average (GPA) in the school setting. Future studies are suggested to analyze EFL learners' literacy performance at the different settings, including formal proficiency language test and school academic performance, for the purpose of exploring the gap existing between proficient learners and less proficient ones. The results may obtain more convincing discoveries for English practitioners, so they can have better understanding of their students learning and thus provide necessary aid for low competence young EFL learners and help them rebuild the confidence in English learning.

\section{References}

[1] Baker, L, Brown, A.L., (1984). Metacognitive skills and reading. In Pearson P.D. (Ed.) Handbook of reading research. 393-394

[2] Bialystok, E., (2002). Acquisition of Literacy in Bilingual Children: A Framework for Research. Language Learning, 52, p. 159-199.

[3] Block, E., (1986). The Comprehension strategies of second language readers. TESOL Quarterly, (20)3, 463491.

[4] Carson, J. E., Carrell, P. L., Silberstein, S., Kroll, B., \& Kuehn, P. A. (1990).Reading-writing relationships in first and second language. TESOL Quarterly, 24 (2), 245-266.

[5] Chou, P.Y (2006). A research on developing young EFL learners' 12 literacy through task-based reading-towriting instruction. Unpublished master thesis. National Cheng Kung University.

[6] Chung, J.J., (2007). A research on facilitating junior high school students' L2 literacy through guided reading and writing instruction. Unpublished master thesis. National Cheng Kung University.

[7] Cummins, J., (1991). Interdependence of first- and second-language proficiency in bilingual children. In E. Bialystok (Ed.), Language processing in bilingual children (pp. 70-89). Cambridge: Cambridge University Press

[8] Eisterhold, J., (1990). Reading-writing connection: toward a description for second language learners. In B. Kroll (Ed.). Second language writing. Cambridge: Cambridge University Press. 
[9] Goodman, K., (1996). On Reading. Heinemann: Portsmouth,NH.

[10] Goodman, K., (1982). Testing in Reading: A General Critique" in K. S. Goodman (Ed.). Language and literacy: The selected writings of Kenneth S. Goodman (pp. 289298). London: Routledge Kegan \& Paul

[11] Hedgcock, J., Atkinson, D., (1993). Differing Reading-writing relationship in L1 and L2 Literacy development? TESOL Quarterly, 27(2) 329-333

[12] Johns, M. A., (1990). Text, role, and context. Cambridge: Cambridge University Press

[13] Krashen, S., (1982). Principles and practice in second language acquisition. New York: Prentice Hall.

[14] Krashen, S., (2004). The power of reading: insights from the research. Portsmouth, H.H.: Heinemann.

[15] Laufer, B., (1992). How much lexis is necessary for reading comprehension? In P. J. L. Arnaud, \& H. Bejoint (Eds.), Vocabulary and applied linguistics (pp. 126-132). London: MacMillan.

[16] Laufer, B., Nation, I.S.P., (1995). Vocabulary size and use: lexical richness in L2 written production. Applied Linguistic 16(3), 307-322.

[17] Laufer, B., (1998) The development of passive and active vocabulary: same or different? Applied linguistic, $19: 255-271$

[18] Nation, P., ( 2001). Learning vocabulary in another language. Cambridge: Cambridge University Press.

[19] Pearson, P. D., Tierney, R. J., (1984).On becoming a thoughtful reader: learning to read like a writer (Reading Education Report No. 50). Urbana, IL: Illinois University at Urbana Champaign

[20] Qian, D., (2002). Investigating the relationship between vocabulary knowledge and academic reading performance: An assessment perspective. Language learning, 52, 513-536.

[21] Reid, J., (1990). Responding to different topic types: a quantitative analysis from a contrastive rhetorical perspective. In B. Kroll (Ed.). Second language writing. (pp. 191-210) Cambridge: Cambridge University Press.

[22] Rivers, W. M., (1975). A Practical Guide to the Teaching of French. NW: Oxford University Press.

[23] Silva, T., (1993). Toward an Understanding of the Distinct Nature of L2 Writing: The ESL Research and Its Implications. TESOL Quarterly, 27(4), 657-677

[24] Schmitt, N., (2000). Vocabulary in language teaching. Cambridge: Cambridge Press

[25] Smith, F., (1985). Reading without nonsense. Cambridge: Cambridge Press.
[26] Stotsky, S., (1983). Research of reading / writing relationships: A synthesis and suggested directions. Language Arts, 60, 568 - 580.

[27] Wallace, C., (1992). Reading. Oxford: Oxford University Press. 